\title{
Wegener's Granulomatosis Autoantibodies Identify a Novel Diisopropylfluorophosphate-binding Protein in the Lysosomes of Normal Human Neutrophils
}

\author{
R. Goldschmeding, ${ }^{\star}$ C. E. van der Schoot, ${ }^{\star}$ D. ten Bokkel Huinink, ${ }^{\star}$ C. E. Hack, ${ }^{\star}$ M. E. van den Ende, ${ }^{\star}$ \\ C. G. M. Kallenberg, ${ }^{\ddagger}$ and A. E. G. Kr. von dem Borne ${ }^{\star \boldsymbol{\xi}}$ \\ ${ }^{*}$ Department of Immunological Haematology, Central Laboratory of the Netherlands, Red Cross Blood Transfusion Service and \\ Laboratory for Experimental and Clinical Immunology, University of Amsterdam, Amsterdam, The Netherlands; ${ }^{\ddagger}$ Department of \\ Clinical Immunology, State University Hospital, Groningen, The Netherlands; and ${ }^{\S}$ Department of Haematology, \\ Academic Medical Centre, University Hospital, Amsterdam, The Netherlands
}

\begin{abstract}
Anti-neutrophil cytoplasmic autoantibodies (ANCA) specifically associated with Wegener's granulomatosis were found to be directed against a saline-soluble glycoprotein triplet that migrates on SDS gels as distinct bands of $M_{\mathrm{r}} 29,000,30,500$, and 32,000 and is present in the azurophilic granules. This antigen was specifically recognized by all cytoplasmic-staining (C)-ANCA-positive sera from patients with Wegener's disease.

C-ANCA antigen bound $\left[{ }^{3} \mathrm{H}\right]$ diisopropylfluorophosphate, which indicates that it is a serine protease, but it could clearly be distinguished from the serine proteases elastase and cathepsin G. Stimulation of cytochalasin B-treated neutrophils with FMLP induced release of $\mathrm{C}-\mathrm{ANCA}$ antigen. This indicates that in vivo $\mathrm{C}$-ANCA might interact with the C-ANCA antigen after its release upon inflammatory stimulation.

We further demonstrate that in some perinuclear staining (P-ANCA) patients' sera autoantibodies against other myeloid lysosomal enzymes can be detected, such as antimyeloperoxidase and antielastase.

C-ANCA and P-ANCA thus represent a novel class of autoantibodies directed against myeloid lysosomal enzymes. The originally described Wegener-specific C-ANCA show an apparently uniform specificity for the 29,000 serine protease. In contrast, $\mathrm{P}$-ANCA may recognize myeloperoxidase as well as elastase and/or other antigens.
\end{abstract}

\section{Introduction}

Immune mechanisms are generally assumed to play a pathogenetic role in Wegener's granulomatosis (WG; reviewed in reference 1). ${ }^{1}$ The most prominent presenting symptoms of the

Address correspondence to Dr. A. E. G. Kr. von dem Borne, \% Publication Secretariat, Central Laboratory of the Netherlands Red Cross Blood Transfusion Service, P. O. Box 9406, 1006 AK Amsterdam, The Netherlands.

Received for publication 7 September 1988 and in revised form 14 July 1989

1. Abbreviations used in this paper: ANCA, anti-neutrophil cytoplasmic autoantibodies; C-ANCA, cytoplasmic-staining ANCA; DFP, diisopropylfluorophosphate; IFT, immunofluorescence test; MPO, myeloperoxidase; NE, neutrophil elastase; P-ANCA, peri- (nuclear)staining ANCA; WG, Wegener's granulomatosis.

J. Clin. Invest.

(c) The American Society for Clinical Investigation, Inc.

$0021-9738 / 89 / 11 / 1577 / 11 \quad \$ 2.00$

Volume 84, November 1989, 1577-1587 disease are localized at sites of contact between the body and the outer world (2-4). Exacerbations appear to be associated with infections (5) and it was recently reported that successful treatment and prevention of exacerbations of WG were achieved with antimicrobial agents $(6,7)$. The granulomatous inflammation as well as the vasculitis and glomerulonephritis of WG show a favorable response to treatment with antiinflammatory and immunosuppressive drugs $(1,2)$. Therefore, derailment of an inflammatory response to certain stimuli seems to be an important factor in the pathogenesis of WG.

In serum of patients with active WG, autoantibodies against intracellular components of neutrophils and monocytes have been detected (8-14). Two distinct staining patterns of these anti-neutrophil cytoplasmic autoantibodies (ANCA) have been observed (Fig. 1). The originally described ANCA produce cytoplasmic staining of ethanol-fixed cytospins of neutrophils (C-ANCA). The perinuclear staining antibodies against MPO, which Falk and Jennette (15) and we (16) independently identified more recently, are called P-ANCA. Indistinguishable P-ANCA staining is observed also with autoantibodies against elastase (16), and against as yet unidentified antigens (17).

Unlike anti-MPO and antielastase (both P-ANCA), CANCA is a specific and sensitive marker for active WG and microscopic polyarteritis (10-14), although exceptions have been noted (18-20). The serum titer of C-ANCA correlates with disease activity (10-14), and exacerbations of WG were invariably found to be preceded by a significant increase of the C-ANCA titer (14). This suggests a possible role of C-ANCA in the pathogenesis of WG and warrants identification of the target antigen(s) of these antibodies.

We here report the partial characterization of C-ANCA antigen as a diisopropylfluorophosphate (DFP)-binding protein (serine protease) of $M_{\mathrm{r}} 29,000$ in the primary granules (lysosomes) of human neutrophils, which is distinct from neutrophil elastase (NE) and cathepsin G.

\section{Methods}

Materials. DFP, EDTA, $N$-ethylmaleimide, benzamidine hydrochloride, iodoacetamide, 6-aminocaproic acid, PMSF, and sodium azide were obtained from Aldrich Chemie (Brussels, Belgium). Percoll, $\mathrm{CNBr}$-activated Sepharose 4B, and protein A-Sepharose CL-4B were purchased from Pharmacia Fine Chemicals (Uppsala, Sweden). Paraformaldehyde was from Merck (Darmstadt, FRG), cytochalasin B, FMLP, NP-40, Triton X-100, and Sigma 104 alkaline phosphatase substrate were obtained from Sigma Chemical Co. (St. Louis, MO). DMSO and Tween-20 were purchased from J. T. Baker Chemicals (Deventer, The Netherlands). ${ }^{125} \mathrm{I}-\mathrm{Na}$ was from the Radiochemical Centre (Amersham, UK), and [ $\left.{ }^{3} \mathrm{H}\right] \mathrm{DFP}$ and $\mathrm{EN}^{3} \mathrm{HANCE}$ were both from New England Nuclear Research Products (Boston, MA). XAR5 


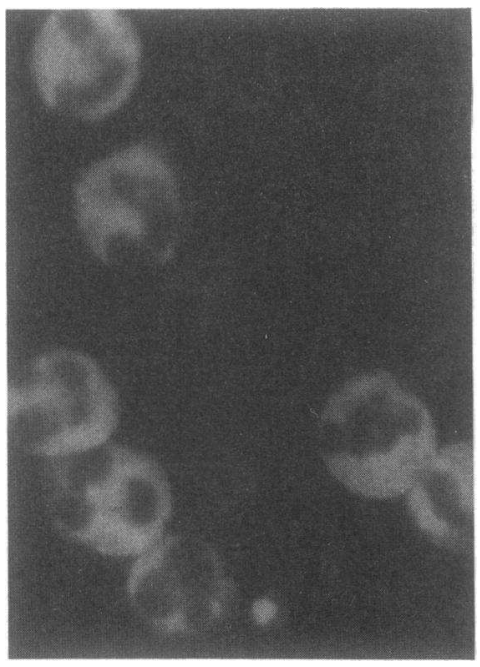

b

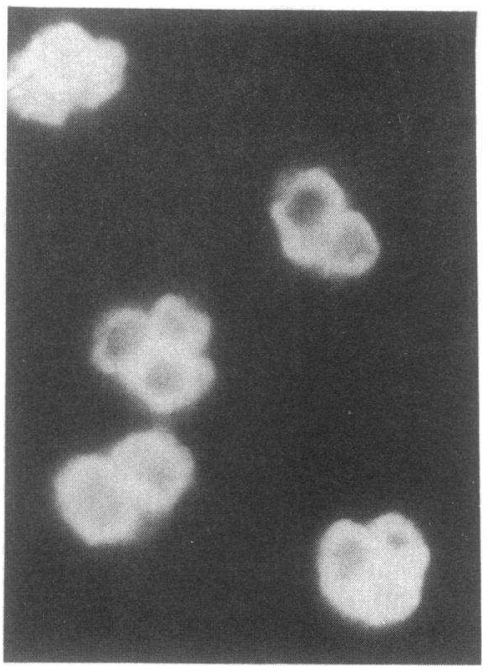

Figure 1. a, Typical staining pattern obtained with serum from a patient with active WG in the standard ANCA immunofluorescence test (C-ANCA pattern). $b$, (Peri-)nuclear staining pattern as can be obtained with antibodies against MPO, cathepsin G, elastase, and nuclear antigens (P-ANCA pattern). film was from Eastman Kodak Co. (Rochester, NY). Neuraminidase was obtained from Behring AG (Marburg, FRG). $\mathrm{N}$-Glycanase was from Genzyme (Boston, MA).

Human sera. For this study we used a pool of sera from 5 healthy donors (normal control), and sera obtained from 91 individual patients. All patients' sera had been submitted to our laboratory for routine ANCA testing. Sera from 41 patients with a diagnosis of WG, established in the referring hospitals on the basis of histopathological findings and/or classical clinical symptoms (21), were selected. These sera contained significant titers of ANCA, producing the characteristic C-ANCA in the standard ANCA immunofluorescence test (IFT); i.e., indirect immunofluorescence on ethanol-fixed, air-dried cytospins of normal donor leukocytes (10). 47 consecutive sera giving negative results in the standard ANCA IFT and 3 selected sera producing PANCA were used as controls.

Serum P-ANCA-1 came from an 80-yr-old woman who presented with malaise, fever, arthralgia, and a skin rash. Skin biopsy showed necrotizing vasculitis of small arteries. Serum P-ANCA-2 came from a 73-yr-old man with general malaise, renal failure, and infiltrative abnormalities on a chest $x$ ray. Muscle biopsy showed an unclassifiable vasculitis. Serum P-ANCA-3 came from a 48-yr-old man with rapidly progressive idiopathic crescentic glomerulonephritis.

Proteins and antisera. Purified human NE (EC 3.4.21.37) prepared from purulent sputum (22) and rabbit anti-NE were kindly provided by Dr. J. A. Kramps, University Hospital, Leiden, The Netherlands. $\mathrm{NE}$ and cathepsin G (EC 3.4.21.20), prepared from chronic myeloid leukemia cells $(23,24)$, were donated by Dr. J. Schalkwijk, University Hospital, Nijmegen, The Netherlands. Purified NE and MPO from purulent sputum, both $>98 \%$ pure, were also obtained from Elastin Products (Pacific, MO). Purified cathepsin G was obtained from Protagen AG (Läufelfringen, Switzerland). Sheep anti-human cathepsin $\mathrm{G}$ was obtained from ICN Biologicals (Lisle, IL).

Mouse MAbs. A mouse MAb against the antigen recognized by human C-ANCA (25) was prepared by intraperitoneal immunization of a $(\mathrm{Balb} / \mathrm{c} \times \mathrm{A} / \mathrm{J}) \mathrm{F}_{1}$ mouse $(\mathrm{CAF} / 1)$ with saline-extracted azurophilic granule proteins (alpha extract; see below). In a sandwich ELISA one of the MAbs thus obtained appeared to bind specifically to the antigen caught from the alpha extract preparation by plastic-coated IgG antibodies purified from a C-ANCA-positive patient's serum, but not to antigen caught by rabbit antielastase. This IgG1 MAb (12.8) was directed against the C-ANCA antigen as demonstrated by sequential immunoprecipitation with C-ANCA-positive patient's sera and it did not bind to biochemically purified NE, cathepsin G, or MPO either in a solid-phase ELISA or in immunoprecipitation experiments (25; to be published in detail elsewhere). MAb NP-57 (IgG1 anti-NE; 26) was a gift of Dr. D. Y. Mason (John Radcliffe Hospital, Oxford, UK). MAb 4.15 (IgG1 anti-MPO) and MAb AME-1 (IgG1 anti-glycophorin A) were produced in our own laboratory.

Antigen preparations. To prevent crosslinking and proteolytic degradation of antigenic material a cocktail of DFP, EDTA, $N$-ethylmaleimide, benzamidine hydrochloride, iodoacetamide, 6-amino-caproic acid, PMSF, and sodium azide (final concentration $1 \mathrm{mM}$ each) was used throughout the preparation of total neutrophil extracts and subcellular fractionation. This cocktail was also added to the supernatants of stimulated neutrophils and to purified NE, cathepsin G, and MPO. In the labeling experiments with $\left[{ }^{3} \mathrm{H}\right] \mathrm{DFP}$ the cocktail was not added until after incubation of the extract with $\left[{ }^{3} \mathrm{H}\right] \mathrm{DFP}$ for $15 \mathrm{~min}$ at $4^{\circ} \mathrm{C}$.

Isolation of neutrophils. Neutrophils were isolated from 200-500 $\mathrm{ml}$ of fresh, citrated blood. The blood was diluted three times with PBS (140 mM NaCl, $9.2 \mathrm{mM} \mathrm{Na}_{2} \mathrm{HPO}_{4}$, and $1.3 \mathrm{mM} \mathrm{NaH}_{2} \mathrm{PO}_{4} ; \mathrm{pH} \mathrm{7.4)}$ and centrifuged over isotonic Percoll of $1.076 \mathrm{~g} / \mathrm{cm}^{3}(1,000 \mathrm{~g}, 20 \mathrm{~min}$, $20^{\circ} \mathrm{C}$ ). The erythrocytes in the pellet fraction were lysed twice with $\mathrm{NH}_{4} \mathrm{Cl}(155 \mathrm{mM}), \mathrm{KHCO}_{3}(10 \mathrm{mM})$, and EDTA $(10 \mu \mathrm{M})$ at $4^{\circ} \mathrm{C}$. The neutrophil suspension thus obtained was kept at $37^{\circ} \mathrm{C}$ for $15 \mathrm{~min}$ to allow sedimentation of spontaneously forming aggregates of damaged or activated cells. The cells remaining in suspension were passed over a piece of autoclaved cotton wool, and the nonadherent cells were collected in siliconized glass tubes.

Indirect immunofluorescence. Ethanol-fixed, air-dried cytospins of purified neutrophils were assayed for binding of anticytoplasmic antibody as described for the standard ANCA IFT (10). Binding of antibodies to the cell membrane of fixed (1\% paraformaldehyde) and unfixed neutrophils in suspension was assayed by the technique of Verheugt et al. (27), with FITC-conjugated $F(a b)_{2}$ fragments of rabbit anti-human IgG (M1040; CLB, Amsterdam, The Netherlands). In the latter technique fluorescence intensity was quantified by continuous flow cytometry.

Induction of neutrophil degranulation. Neutrophils $\left(2 \times 10^{7} / \mathrm{ml}\right.$ in a medium that consisted of $138 \mathrm{mM} \mathrm{NaCl}, 2.7 \mathrm{mM} \mathrm{KCl}, 8.1 \mathrm{mM}$ $\mathrm{Na}_{2} \mathrm{HPO}_{4}, 1.5 \mathrm{mM} \mathrm{KH}_{2} \mathrm{PO}_{4}, 0.6 \mathrm{mM} \mathrm{CaCl}_{2}, 1.0 \mathrm{mM} \mathrm{MgCl}$, and 5.5 $\mathrm{mM}$ glucose) were preincubated for $10 \mathrm{~min}$ at $37^{\circ} \mathrm{C}$ with cytochalasin B $(10 \mu \mathrm{g} / \mathrm{ml})$ diluted from a stock solution of $10 \mathrm{mg} / \mathrm{ml}$ in DMSO. To control cells vehicle alone was added. Subsequently, cytochalasin Btreated and untreated neutrophils were stimulated with FMLP (20 $\mathrm{ng} / \mathrm{ml}$ ) for $20 \mathrm{~min}$ at $37^{\circ} \mathrm{C}$. The reaction was terminated by centrifugation at $0^{\circ} \mathrm{C}(10 \mathrm{~min}, 1,000 \mathrm{~g})$. Release of the cytosolic enzyme lactate dehydrogenase (L-lactate:NAD oxidoreductase, E.C.1.1.1.27) served as a control for cell lysis during the experiment. Recovery of azurophilic 


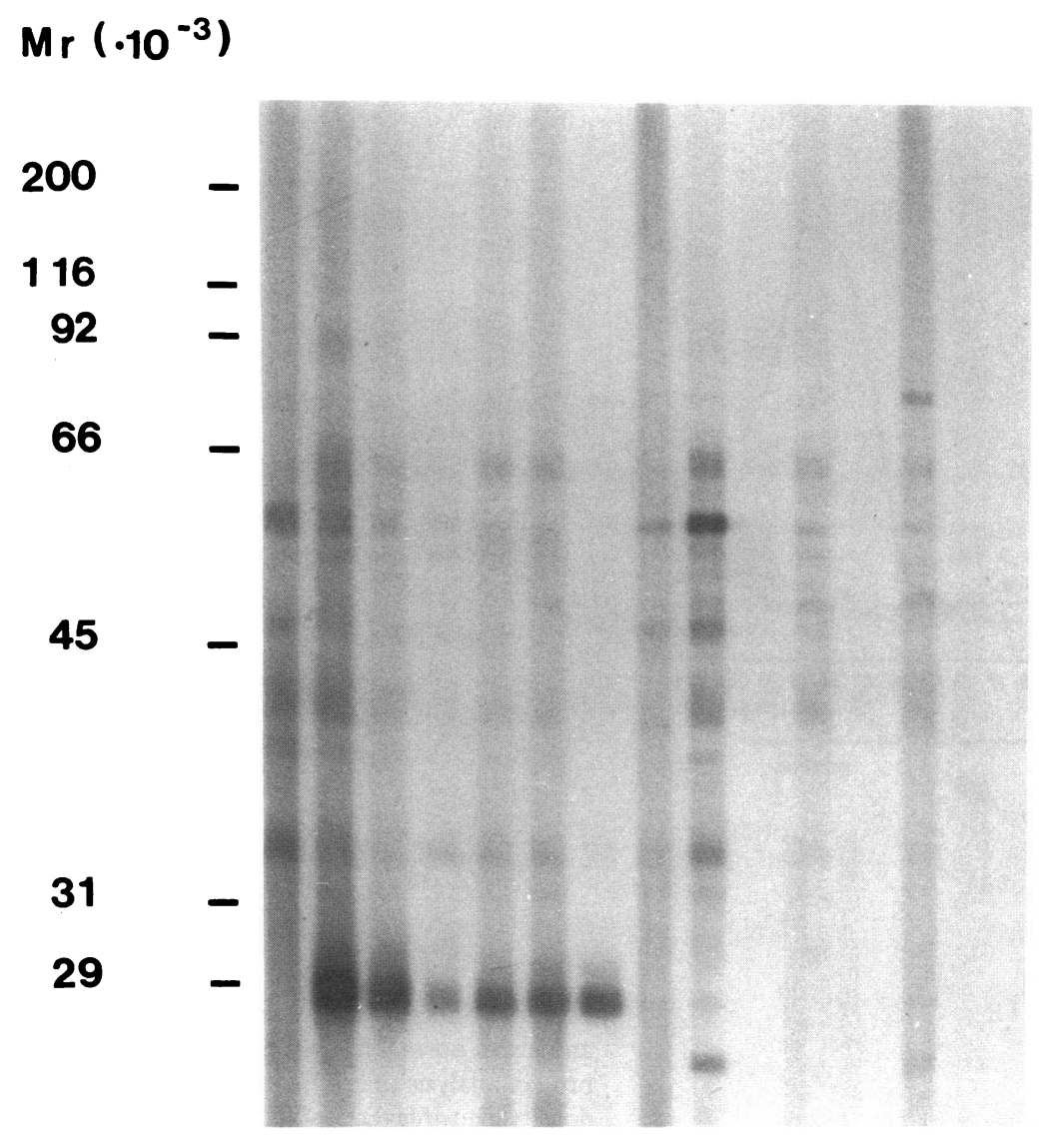

ANCA (IF): $\quad-+++++++-\ldots-+---$
Figure 2. Western blot analysis of $1 \%$ NP-40 lysate of normal donor neutrophils. Extracts from purified neutrophils were prepared at concentrations equivalent to $2 \times 10^{8}$ cells $/ \mathrm{ml}$ by incubation for $1 \mathrm{~h}$ at $4^{\circ} \mathrm{C}$ in $1 \%$ (vol/vol) NP-40 in $20 \mathrm{mM}$ Tris, pH 6.8. The extracts were cleared by centrifugation ( 10 min, $12,000 \mathrm{~g}$ ) in the cold. For Western blot analysis samples from these extracts were electrophoresed at a concentration equivalent to $2 \times 10^{7}$ cells/ $\mathrm{cm}$ gel. Lanes $A$ and $N$, normal control sera; lanes $B-G$, C-ANCA-positive sera; lane $H$, serum containing multiple HLA antibodies; lanes $I-K$, sera containing antibodies against three different alloantigens (NB1, NA1, and ND1) expressed on neutrophil plasma membranes; lane $L$, serum containing antinuclear antibodies; lane $M$, serum containing antimitochondrial antibodies; and lane $O$, ANCAnegative serum from a patient with unclassified vasculitis. granule proteins was estimated by determination of $\beta$-glucuronidase $(\beta$-D-glucuronide glucuronohydrolase, E.C. 3.2.1.31) activity (28). For preparation of samples for Western blot analysis the supernatants were concentrated 50-fold in a Minicon macrosolute concentrator (Amicon Corp., Danvers, MA) in the presence of $0.1 \%$ SDS.

Subcellular fractionation of neutrophils. Subcellular fractionation of neutrophils by Percoll density-gradient centrifugation and marker protein analysis in the fractions thus obtained were performed in essence as described by Borregaard et al. (29). On the basis of distribution of marker proteins gradient fractions were combined to form four pools: pool $\alpha$ contained only azurophilic granules, pool $\beta$ contained the specific granules plus some azurophilic granules, pool $\gamma$ contained the plasma membranes and phosphasomes, and pool $\delta$ contained the cytosol. Percoll was removed by ultracentrifugation (60 $\min , 220,000 \mathrm{~g}$ ).

From pools $\alpha, \beta$, and $\gamma$ the insoluble membrane proteins were separated from soluble proteins as follows. After six freeze-thaw cycles the pools were extracted for $45 \mathrm{~min}$ on ice in a $50 \mathrm{mM}$ glycine, $10 \mathrm{mM}$ $\mathrm{Na}_{2} \mathrm{HPO}_{4} / \mathrm{NaH}_{2} \mathrm{PO}_{4}$ buffer of $\mathrm{pH} 6.8$, containing $3.5 \mathrm{M}$ ureum and 1 $\mathrm{M} \mathrm{KCl}$. Thereafter, soluble and insoluble materials were separated by centrifugation at $220,000 \mathrm{~g}$ for $90 \mathrm{~min}$ and dialyzed against PBS (29).

Western blotting. For Western blot analysis whole cell extracts, subcellular fractions, and supernatants of stimulated neutrophils were electrophoresed under nonreducing conditions on 1.5-mm SDS polyacrylamide gels (10 or $12.5 \%)$ at concentrations equivalent to $2 \times 10^{7}$ cells/cm gel. NP-40 extracts $(1 \%)$ of whole neutrophils $\left(2 \times 10^{8}\right.$ cells/ $\mathrm{ml}$ ) were prepared for gel electrophoresis by addition of an equal volume of concentrated sample buffer (7\% SDS, $0.18 \mathrm{M}$ Tris/HCl, pH 6.8,
$9 \%$ glycerol, and $0.5 \mathrm{mg} / \mathrm{ml}$ bromophenol blue) to achieve a sevenfold excess of SDS over NP-40. Properly diluted subcellular fractions and concentrated supernatants from stimulated neutrophils were mixed directly with sample buffer. All samples were boiled for 2 min before electrophoresis. Transfer to nitrocellulose and detection of antibody binding with ${ }^{125}$ I-labeled mouse MAb against human IgG (MH 16-1; CLB, Amsterdam, The Netherlands) were performed as described (30).

Immunoprecipitation. After dialysis against PBS the extracts and membrane preparations from subcellular neutrophil fractions (pools $\alpha, \beta$, and $\gamma$ ) were supplemented with $\mathrm{NaCl}, \mathrm{SDS}$, and Triton $\mathrm{X}-100$ to final concentrations of $0.5 \mathrm{M}, 0.5 \%(\mathrm{wt} / \mathrm{vol})$, and $1 \%(\mathrm{wt} / \mathrm{vol})$, respectively. The samples thus obtained were radiolabeled with ${ }^{125} \mathrm{I}$ by the iodogen method (31) and assayed by immunoprecipitation with the protein A method described by Huisman et al. (32). Immunoprecipitation with sheep anti-cathepsin $G$ was performed with antibodies linked covalently to $\mathrm{CNBr}$-activated Sepharose 4B. The radiolabeled preparations were diluted in immunoprecipitation buffer $(4 \%$ [wt/vol] BSA, $1 \%$ [wt/vol] Triton X-100, 0.5\% [wt/vol] SDS, and $0.5 \mathrm{M} \mathrm{NaCl}$ in PBS). 250- $\mu$ l aliquots were incubated overnight with either anti-cathepsin G-Sepharose or serum $\left(5 \mu \mathrm{l} /\right.$ precipitation) at $4^{\circ} \mathrm{C}$, and subsequently with protein A-Sepharose CL-4B ( $5 \mathrm{mg} /$ precipitation) for another $3 \mathrm{~h}$. For use in sequential immunoprecipitation experiments, IgG preparations from antisera or ascitic fluid were coupled covalently to $\mathrm{CNBr}$-activated Sepharose 4B. In these experiments the incubation time for each step was reduced to $60 \mathrm{~min}$. The Sepharose beads were thoroughly washed in immunoprecipitation buffer, PBS, and $10 \mathrm{mM}$ Tris- $\mathrm{HCl}, \mathrm{pH} 6.8$, and subsequently centrifuged through 10 and $20 \%$ sucrose solutions in $10 \mathrm{mM}$ Tris- $\mathrm{HCl}, \mathrm{pH} 6.8$. Finally, the beads were 
a

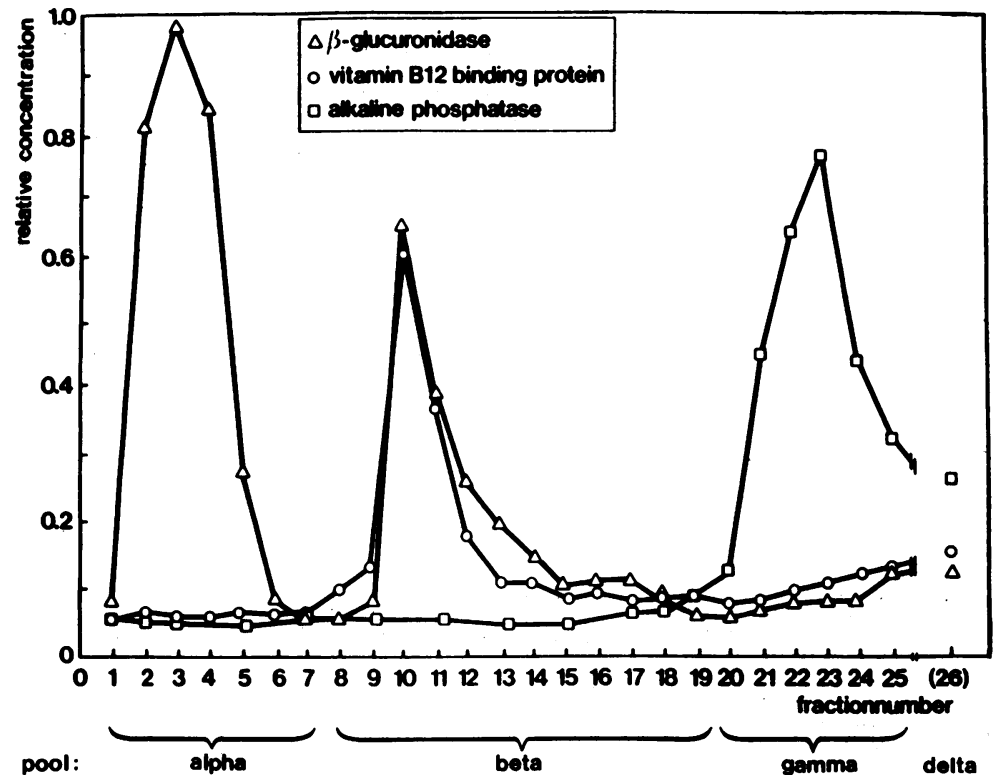

b

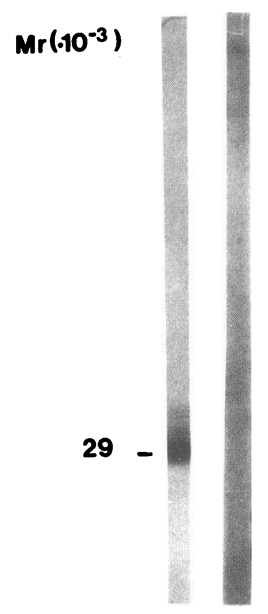

ANCA

(IF):
$+$

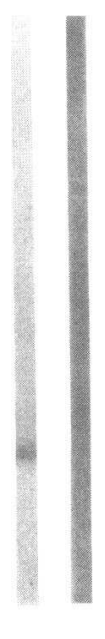

boiled for $2 \mathrm{~min}$ with sample buffer and centrifuged. The supernatants were electrophoresed in 10 or $12.5 \%$ polyacrylamide gels. Gels were stained in $0.18 \%$ Coomassie brilliant blue R-250 in 25\% methanol, $10 \%$ acetic acid and destained in the same solvent mixture. Gels were then washed in water containing $20 \%$ glycerol, dried under vacuum, and exposed to Kodak XAR5 film.

Deglycosylation of immunoprecipitated antigens. Radiolabeled ${ }^{125}$ I-antigens immunoprecipitated with rabbit anti-NE, sheep anticathepsin G, or ANCA-positive patient's serum were treated with neuraminidase and with $N$-glycanase under reducing conditions as described by Elder and Alexander (33).

$\left[{ }^{3} \mathrm{H}\right] D F P$ labeling of serine proteases. Lysosomal serine proteases were labeled with $\left[{ }^{3} \mathrm{H}\right] \mathrm{DFP}$ by incubation of a $1 \%$ Triton $\mathrm{X}-100$ lysate of purified azurophilic granules in $20 \mathrm{mM}$ Tris/ $\mathrm{HCl}, \mathrm{pH} 6.8$, at a concentration equivalent to $\sim 1 \times 10^{8}$ neutrophils $/ \mathrm{ml}$, in the presence of $\left[{ }^{3} \mathrm{H}\right] \mathrm{DFP}(100 \mu \mathrm{M}$, sp act $3.5 \mathrm{Ci} / \mathrm{mmol})$ for $15 \mathrm{~min}$ at $4^{\circ} \mathrm{C}$. For fluorography of material labeled with $\left[{ }^{3} \mathrm{H}\right] \mathrm{DFP}$ alone gels (stained and destained as described above) were immersed for $30 \mathrm{~min}$ in EN $^{3}$ HANCE and washed for $30 \mathrm{~min}$ in water. Subsequently the gels were dried and exposed to Kodak XAR5 film.

Solid-phase ELISAs. Saline-extracted azurophilic granule proteins were coated overnight to microtiter plates (M129A; Dynatech Laboratories Inc., Alexandria, VA) at a protein concentration of $10 \mu \mathrm{g} / \mathrm{ml}$ in
Figure 3. Subcellular distribution of the C-ANCA antigen in normal human neutrophils. $a$, Marker protein analysis of cell fractions obtained by Percoll density centrifugation of nitrogen-cavitated neutrophils. Fractions were pooled to form preparations that contained only azurophilic granules (alpha), specific granules with some contaminating azurophilic granules (beta), plasma membranes and phosphosomes (gamma), and cytosol (delta). $b$, Western blot analysis. Pools $\alpha, \beta, \gamma$, and $\delta$ were equally diluted in $10 \mathrm{mM}$ Tris/ $\mathrm{HCl}, \mathrm{pH} 6.8$, to yield a concentration comparable to that of $2 \times 10^{7}$ cells $/ \mathrm{cm}$ gel as calculated from the $\beta$-glucuronidase content of pool $\alpha$.
0.1 M carbonate buffer, pH 9.6. Purified NE and cathepsin G were coated at a concentration of $1 \mu \mathrm{g} / \mathrm{ml}$. All antibody dilutions (human sera 1:20, rabbit and sheep antibodies 1:200, and mouse MAbs [ascitic fluid $1: 1,000]$ ) were made in PBS supplemented with $5 \%$ normal goat serum, $0.25 \%$ Tween-20, and $0.15 \mathrm{M} \mathrm{NaCl}$ (ELISA incubation buffer). Between incubations ( $1 \mathrm{~h}$ at room temperature) the plates were washed five times with $0.05 \%$ Tween- 20 in PBS. Primary antibody binding was detected with alkaline phosphatase-conjugated secondary antibodies (Jackson, West Grove, PA) and "Sigma 104."

Sandwich ELISAs. Mouse MAbs (ascites, diluted 1:1,000) were immobilized to microtiter plates coated with an IgG fraction of goat antiserum against mouse Ig (Jackson Immuno Research Laboratories Inc., Avondale, PA) at a concentration of $10 \mu \mathrm{g} / \mathrm{ml}$ in coating buffer. Immobilized MAbs were allowed to catch their respective antigens from the preparation of saline-extracted azurophilic granule proteins $(10 \mu \mathrm{g} / \mathrm{ml}$ in ELISA incubation buffer) during a 1-h incubation at room temperature. Further procedures were as given for solid-phase ELISAs.

In the reciprocal experiment IgG purified from healthy control serum and IgG purified from WG serum with a titer of $\geq 1,024$ in the standard ANCA IFT were coated directly to microtiter plates (10 $\mu \mathrm{g} / \mathrm{ml})$. After incubation with saline-extracted azurophilic granule proteins ( $10 \mu \mathrm{g} / \mathrm{ml}$ in ELISA buffer), caught antigen was detected with 


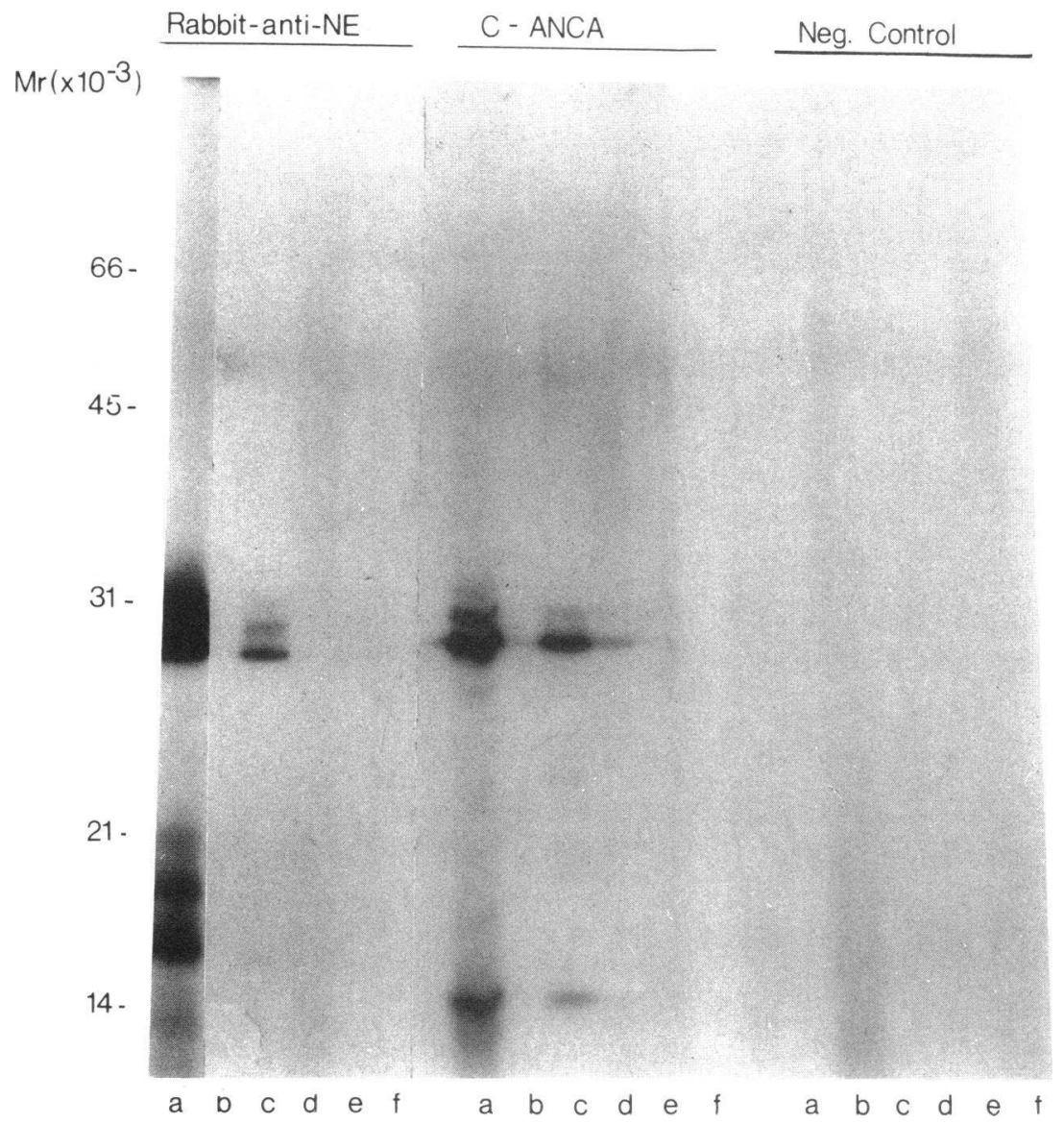

Figure 4. Identification of the ANCA antigen as a soluble constituent of the azurophilic granules. Urea- $\mathrm{KCl}$ extracts and membrane preparations from the different pools of Percoll gradient fractions were radioiodinated and tested by immunoprecipitation with rabbit anti-NE, CANCA-positive WG serum, and a C-ANCAnegative patient's control serum. Lane $a$, extract of the $\alpha$-fraction; lane $c$, extract of the $\beta$-fraction; lane $e$, extract of the $\gamma$-fraction; lanes $b, d$, and $f$, the membrane preparations of the respective fractions. poly- or monoclonal antibodies against elastase, cathepsin G, and CANCA antigen.

\section{Results}

Determination of the apparent molecular weight of the antigen recognized by $C-A N C A$. The apparent molecular weight of the antigen recognized by C-ANCA was determined by Western blot analysis on NP-40 extracts of whole neutrophils. A protein band of $M_{\mathrm{r}} 29,000$ was specifically stained by all six CANCA-positive WG sera, but not by the ANCA-negative patients' sera or normal control sera (Fig. 2).

Subcellular localization of the $C-A N C A$ antigen. Plasma membrane expression of the antigen identified by C-ANCApositive sera was studied by indirect immunofluorescence on neutrophils in suspension (not shown). Significant staining of the plasma membrane was not observed under either standard conditions or conditions preventing capping and phagocytosis (low temperature and treatment of the cells with cytochalasin B). Comparable results were obtained when paraformaldehyde-fixed or unfixed cells were tested. Control experiments indicated that neither paraformaldehyde fixation nor incubation at low temperature and/or cytochalasin B treatment affected antibody binding to cytospinned neutrophils. This suggested that the antigen recognized by WG sera is not expressed on the plasma membrane of neutrophils.

The subcellular distribution of C-ANCA antigen was studied by Percoll density-gradient centrifugation of nitrogen-cavitated neutrophils. Western blot analysis of these subcellular fractions (Fig. $3 a$ ) revealed that in the $\alpha$-fraction (which contained only azurophilic granules) a protein with $M_{\mathrm{r}} 29,000$ was specifically recognized by C-ANCA-positive sera. A similar protein was found in the $\beta$-fraction, although at a lower concentration. This was probably due to contamination of the $\beta$-fraction, containing the specific granules, with some azurophilic granules. In the $\gamma$ - (membrane-phosphasome) and $\delta$ (cytosol) fractions no ANCA-reactive proteins were found (Fig. $3 \mathrm{~b}$ ). Thus, the C-ANCA antigen apparently copurified with azurophilic granules.

Subsequently, insoluble membrane proteins were separated from soluble proteins by extraction of the $\alpha-, \beta$ - and $\gamma$-fractions in a buffer containing $3.5 \mathrm{M}$ urea and $1 \mathrm{M} \mathrm{KCl}$ or in PBS. In radioimmunoprecipitation experiments (Fig. 4) and Western blots (not shown) the C-ANCA antigen was almost exclusively recovered from the extracts (obtained with either buffer) of the $\alpha$-fraction, and trace amounts were again found in the extract of the $\beta$-fraction but not in that of the $\gamma$-fraction. The membrane preparations of the different fractions did not contain detectable amounts of the antigen. In the experiment shown in Fig. 4 it can be seen that immunoprecipitated CANCA antigen in fact migrates as a triplet of bands with $M_{\mathrm{r}}$ $29,000,30,500$, and 32,000 (see below). Thus, the C-ANCA antigen was found to be a saline-soluble protein present in azurophilic granules of normal neutrophils.

Immunoprecipitation results with different patients' sera and correlation with staining patterns in the ANCA-IFT. 35 sera (12 C-ANCA-positive WG sera and 23 ANCA-negative 


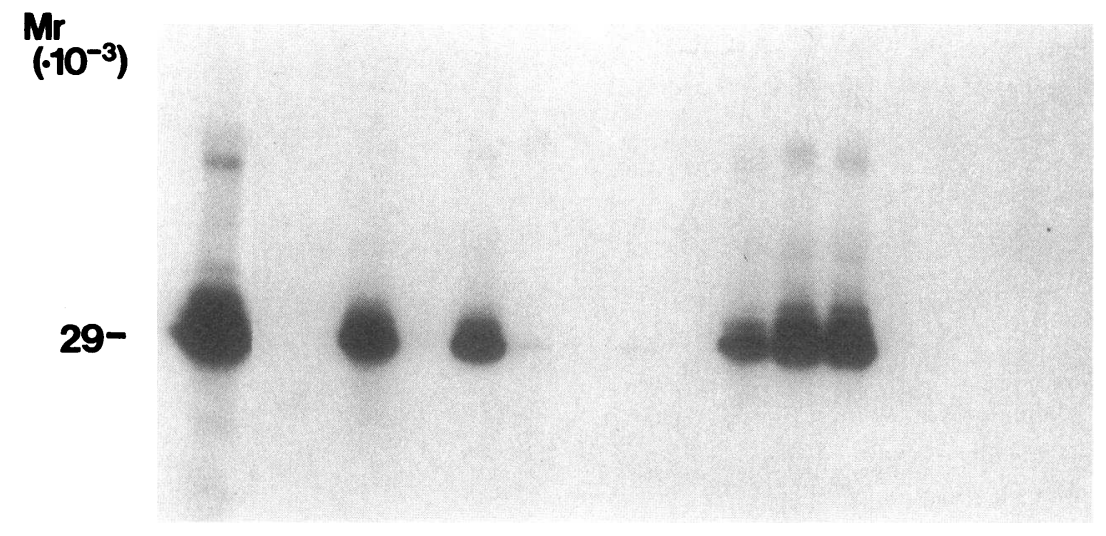

ANCA

(IF): $-+--+-+----+++-\cdots$

$\mathrm{Mr}$

$\left(\cdot 10^{-3}\right)$

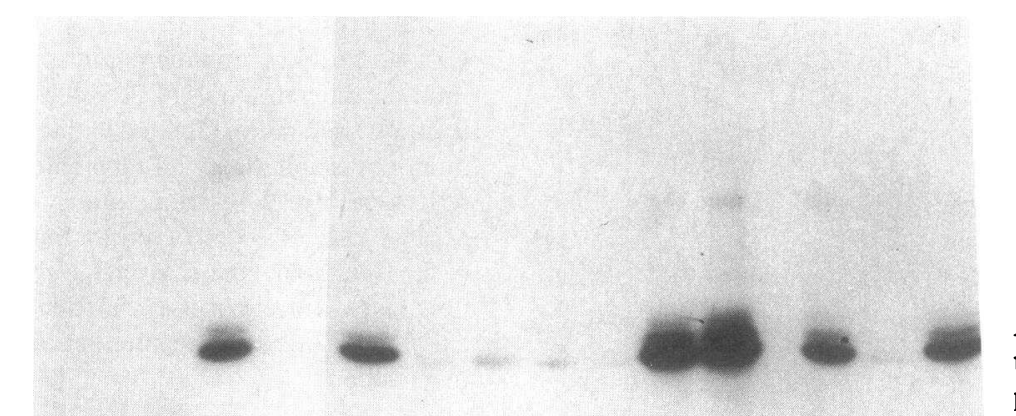

29-

ANCA

(IF):

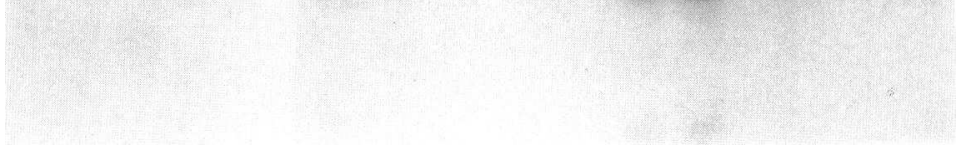

-

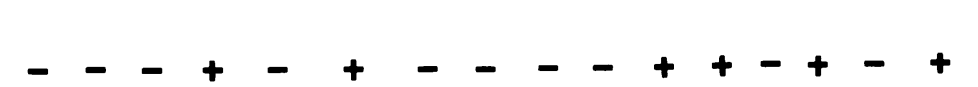

Figure 5. Specificity of C-ANCA-positive patients' sera for the saline-soluble 29,000 azurophilic granule protein. $12 \mathrm{C}$-ANCA-positive sera (lanes marked $I F:+$ ) and 23 ANCA-negative sera (lanes marked $I F:-$ ), each from individual patients, were tested for immunoprecipitation of C-ANCA antigen from a ${ }^{125}$ I-labeled preparation of saline-extracted azurophilic granule proteins. control sera) were tested for their capability to immunoprecipitate the C-ANCA antigen from a ${ }^{125}$ I-labeled saline extract of purified azurophilic granules under stringent conditions (1\%

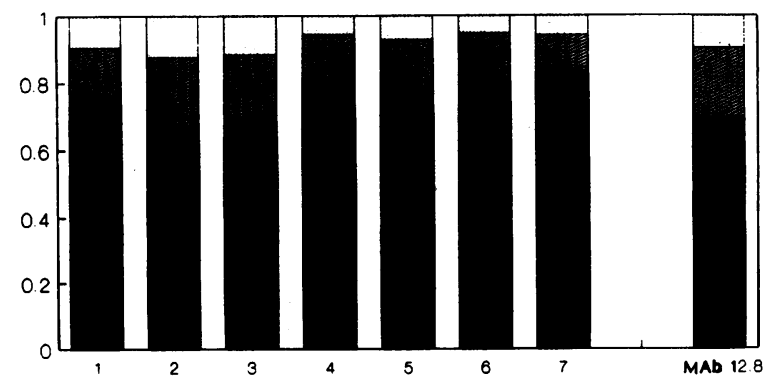

Figure 6. Quantitation of the relative amounts of radioactivity in the individual bands of the C-ANCA antigen triplet. Radiolabeled alpha extract was immunoprecipitated by seven different patients' sera and by MAb 12.8. The precipitates were electrophoresed, the gels dried, and the three different bands excised. Radioactivity was determined in a gamma counter. Results are expressed as fraction of total radioactivity in each precipitated triplet. $\mathbf{}, 29,000$ (mean $=0.72$, SD $=0.06) ; 0,30,500($ mean $=0.20, \mathrm{SD}=0.04) ; \square, 32,000($ mean $=$ $0.08, \mathrm{SD}=0.03$ ).
Triton X-100, $0.5 \%$ SDS, $0.5 \mathrm{M} \mathrm{NaCl}$ ). Only the 12 cytoplasmic-staining WG sera specifically precipitated a band at $M_{\mathrm{r}}$ 29,000 . The stronger sera precipitated two additional bands at $M_{\mathrm{r}} 30,500$ and 32,000 (Fig. 5). Upon longer exposure of the $\mathrm{x}$-ray films these additional bands became visible in the electrophoresed immunoprecipitates of the weaker C-ANCA sera as well. With sera containing high titers of C-ANCA the 29,000 as well as the 30,500 and 32,000 bands could also be visualized in Western blots. The relative amount of the three bands was approximately the same in all immunoprecipitates (Fig. 6). Together these findings suggest that the C-ANCA antigen is expressed on each of three related molecules (possibly isoenzyme forms) that constitute the C-ANCA triplet. In immunoprecipitations with C-ANCA-positive sera and with MAb 12.8 apart from the triplet weak bands of $M_{\mathrm{r}} 50,000$ and 14,000 were also sometimes detected. The nature of these extra bands has not yet been studied, but they could represent dimers and fragments of C-ANCA antigen.

Immunoprecipitates were obtained from a single preparation of radiolabeled $\alpha$-extract with C-ANCA-positive WG sera and selected P-ANCA-positive sera. The precipitations were analyzed in parallel to study the antigenic specificities of the autoantibodies associated with the different staining patterns. 


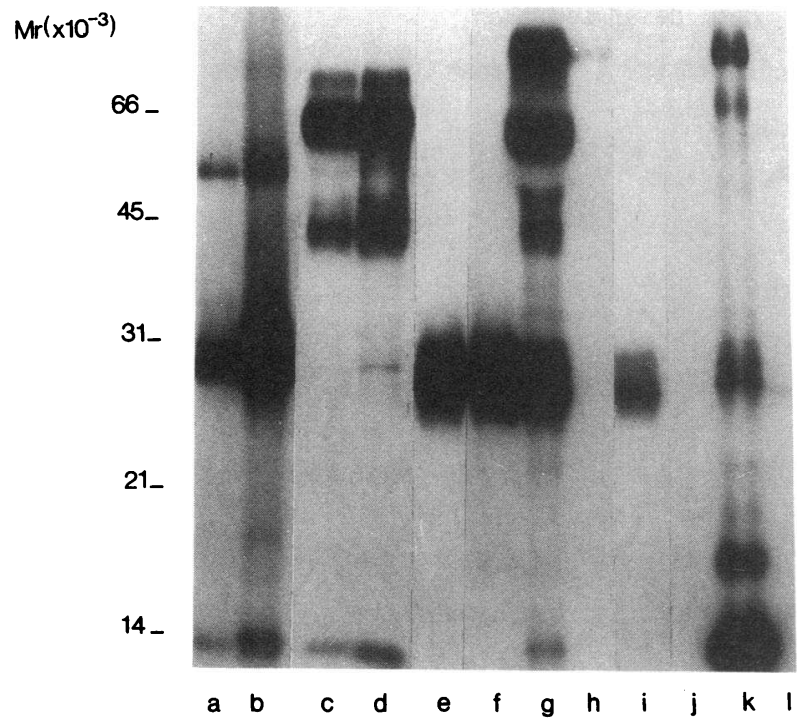

Figure 7. Immunoprecipitation of different myeloid lysosomal enzymes by patients' C-ANCA or P-ANCA in the IFT. Anti-MPO and antielastase MAbs were included as controls. Lane $a$, MAb 12.8; lane $b$, C-ANCA-positive WG serum; lane $c$, MAb 4.15 (anti-MPO); lane $d$, serum P-ANCA-1; lane $e$, MAb NP57 (anti-NE); lane $f$, serum PANCA-2; lane $g$, serum P-ANCA-3; lane $h$, normal control serum (human); lane $i$, sheep anti-cathepsin G; lane $j$, normal sheep serum; lane $k$, rabbit antilysozyme (Dako); lane $l$, normal rabbit serum. In the immunoprecipitate in lane $g$, obtained with serum P-ANCA-3, an as yet unidentified high molecular weight band is seen in addition to the MPO and NE bands.

Immunoprecipitates obtained with MAbs against MPO and elastase and with polyclonal sheep anti-cathepsin $G$ and rabbit antilysozyme were included as controls (Fig. 7). Evidently a characteristic cytoplasmic staining pattern in the ANCA IFT is strictly associated with immunoprecipitation of the C-ANCA antigen triplet. In contrast, P-ANCA sera may or may not

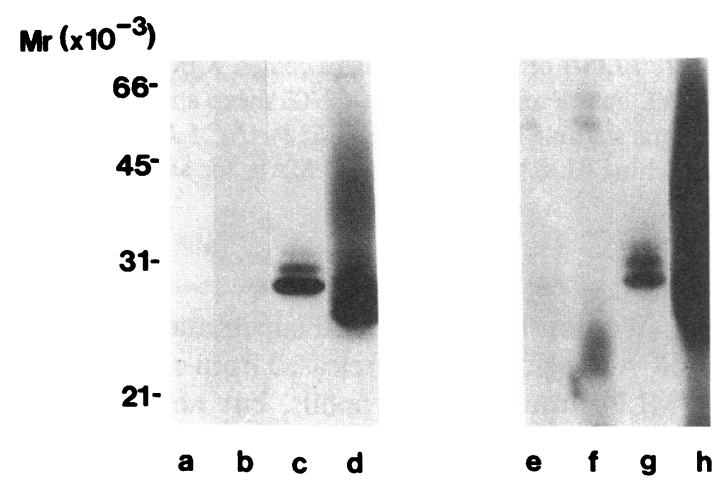

Figure 8. Affinity labeling of NE and C-ANCA-antigen with [ $\left.{ }^{3} \mathrm{H}\right] \mathrm{DFP}$. Analysis by immunoprecipitation (electrophoresis under nonreducing conditions). A Triton X-100 lysate of purified azurophilic granules was treated with $\left[{ }^{3} \mathrm{H}\right] \mathrm{DFP}$ for $15 \mathrm{~min}$ at $4^{\circ} \mathrm{C}$. Part of this preparation was additionally labeled with ${ }^{125} \mathrm{I}$. Lanes $a-d$, Fluorograph of immunoprecipitated azurophilic granule proteins labeled only with $\left[{ }^{3} \mathrm{H}\right] \mathrm{DFP}$. Lanes $e-h$, Immunoprecipitated azurophilic granule proteins double-labeled with $\left[{ }^{3} \mathrm{H}\right] \mathrm{DFP}$ and ${ }^{125} \mathrm{I}$. Lanes $a$ and $e$, Human control serum; lanes $b$ and $f$, rabbit control serum; lanes $c$ and $g$, C-ANCA-positive serum; lanes $d$ and $h$, rabbit anti-NE. precipitate MPO or elastase, and even some of these sera are found to precipitate both enzymes (serum P-ANCA-3). Moreover, antibodies precipitating MPO or elastase may be present in combination with antibodies precipitating C-ANCA antigen (not shown).

$\left[{ }^{3} H\right] D F P$ binding by the $C$-ANCA antigen. Like C-ANCA antigen the serine proteases present in neutrophil lysosomes have apparent molecular weights near 30,000 and are soluble in saline. To investigate whether the C-ANCA antigen might be a serine protease, it was immunoprecipitated from a $\left[{ }^{3} \mathrm{H}\right]-$ DFP-labeled extract of azurophilic granules. As a control, the same preparations were immunoprecipitated with rabbit antiNE (Fig. 8).

C-ANCA serum was found to precipitate three $\left[{ }^{3} \mathrm{H}\right] \mathrm{DFP}-$ labeled bands that exactly matched the three bands immunoprecipitated from a sample of the same $\left[{ }^{3} \mathrm{H}\right]$ DFP-labeled preparation that had additionally been labeled with ${ }^{125} \mathrm{I}$. The three bands precipitated from both preparations by antielastase clearly displayed a higher electrophoretic mobility than the C-ANCA-antigen triplet.

Discrimination between the C-ANCA antigen, NE, and cathepsin $G$. The relation between NE, cathepsin $G$, and the C-ANCA antigen was investigated in four independent experiments (Fig. 9).

Sequential immunoprecipitation with polyclonal rabbit antielastase, followed by sheep anti-cathepsin G, and finally by a C-ANCA-positive WG patient's serum or MAb 12.8 (Fig. 9 a) showed that the C-ANCA antigen is immunologically different from elastase and cathepsin G. This was confirmed when the order of incubations was reversed. Moreover, the three antigens had clearly different electrophoretic mobilities under both reducing and nonreducing conditions.

Selective deglycosylation of immunoprecipitated elastase, cathepsin G, and C-ANCA antigen showed that all three proteins contain $N$-linked glycans (Fig. 9 b). Moreover, the deglycosylated samples showed different electrophoretic mobility, which indicates that the C-ANCA antigen is not a glycosylation variant of either elastase or cathepsin $\mathrm{G}$.

The reactivity of patients' sera, MAbs, rabbit antielastase serum, and sheep anti-cathepsin $G$ with crude saline extract from purified azurophilic granules and with biochemically purified elastase and cathepsin $G$, was tested in solid-phase ELISAs (Fig. 9 c). C-ANCA-positive patients' sera did not bind to biochemically purified elastase or cathepsin G. Also in antigen-capture ELISAs (Fig. $9 d$ ) C-ANCA antigen proved to be distinct from elastase and cathepsin G.

Reactivity of routinely submitted patients' sera with antigens caught by different MAbs. Selected sera from 91 individual patients (submitted to our laboratory for routine ANCA testing) were tested in sandwich ELISAs with MAbs 12.8 (anti-C-ANCA antigen), NP57 (antielastase), and 4.15 (antiMPO), and with the negative control MAb AME-1 (anti-glycophorin A) as the antigen-catching antibodies. All C-ANCApositive sera $(n=41)$ showed specific binding only to the antigen caught by MAb 12.8 (Fig. 10). In contrast, none of the ANCA-negative control sera $(n=47)$ bound to the caught C-ANCA antigen or to MAb caught elastase or MPO. The reactivity of the three selected P-ANCA-positive sera in the various ELISAs confirmed their specificities as determined by immunoprecipitation and solid-phase ELISA (Figs. 7 and 9, $c$ and $d$ ). 

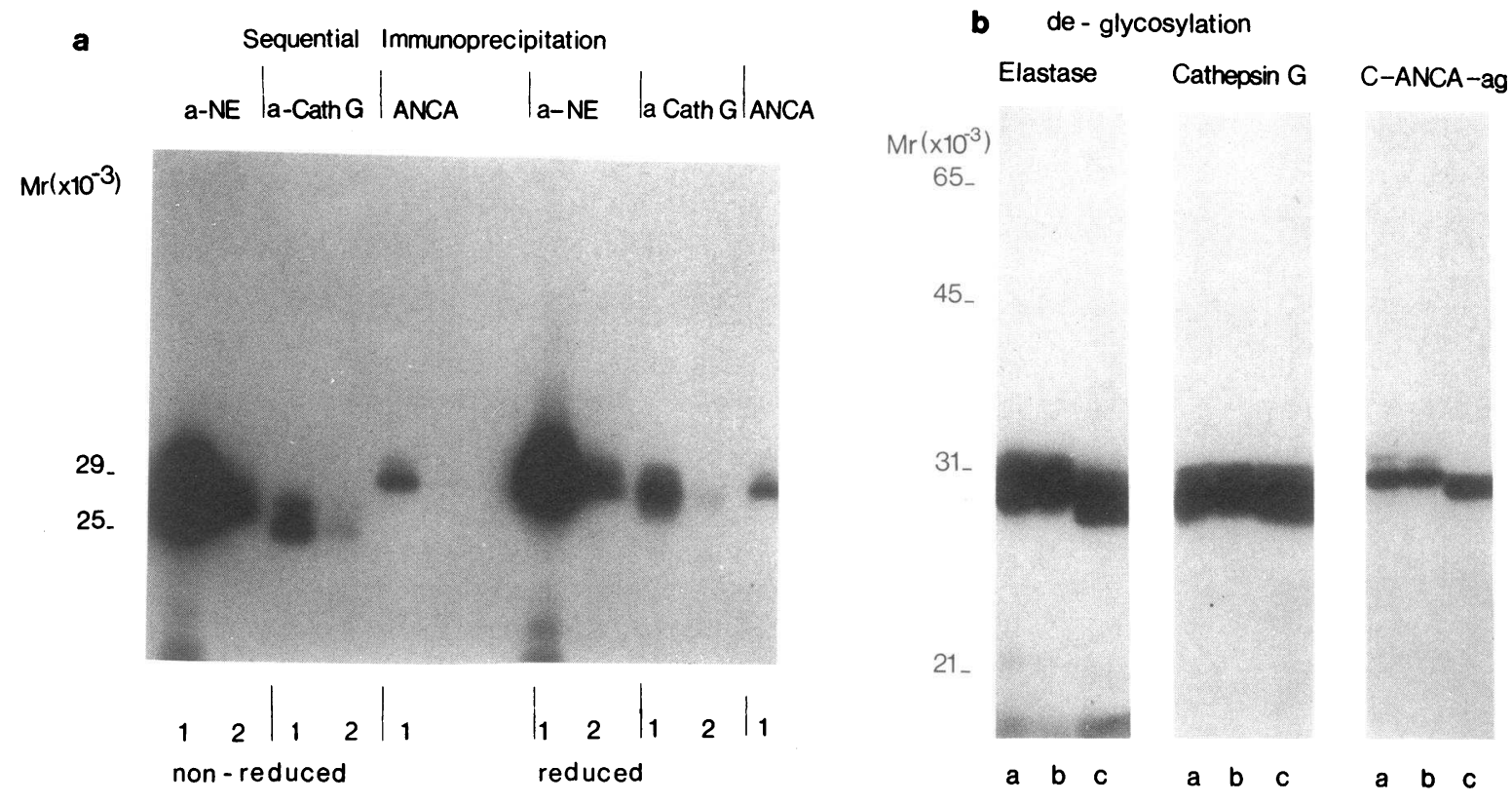

c
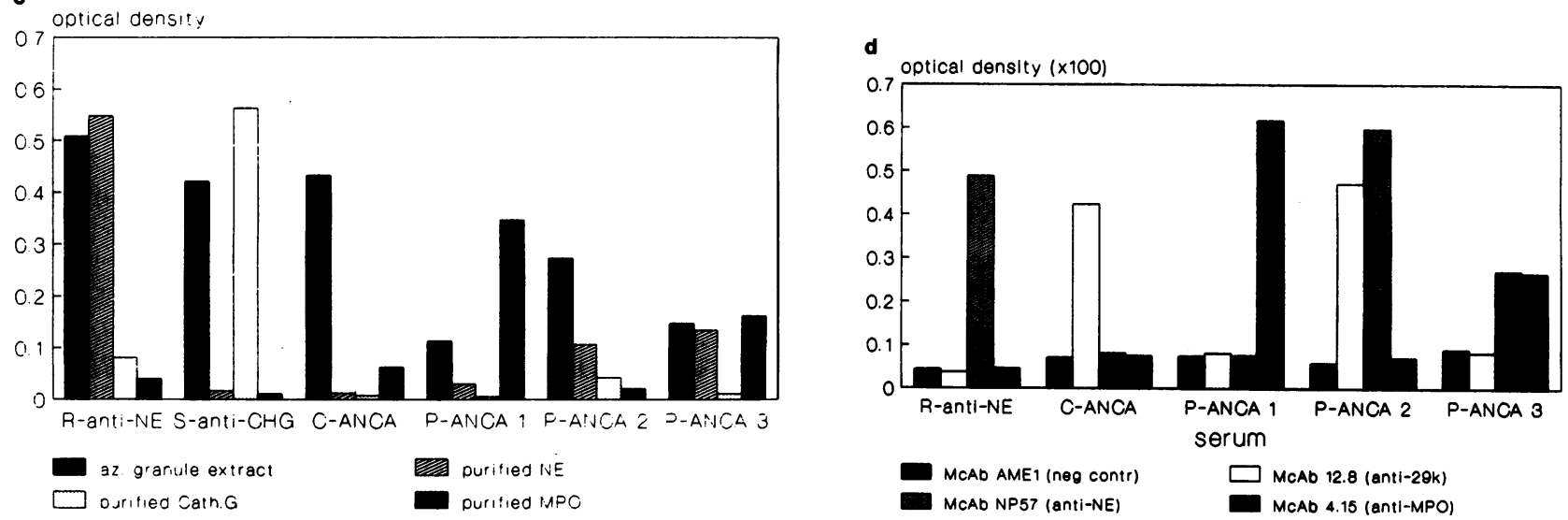

Figure 9. Discrimination between C-ANCA antigen, elastase, and cathepsin G. $a$, Sequential immunoprecipitation of NE, cathepsin G (cathG), and C-ANCA antigen (ANCAag). $b$, Treatment of immunoprecipitated NE, cathepsin G, and C-ANCA antigen with neuraminidase and $N$-glycanase. SDS-PAGE under reducing conditions. Lane $a$, Untreated samples; lane $b$, samples treated with neuraminidase to remove sialic acid; lane $c$, samples treated with $N$-glycanase to remove asparagine-linked sugars. $c$, Solid-phase ELISA on microtiter plates coated with crude saline extract from azurophilic granules, and with purified NE, cathepsin G, and MPO. $R$-anti-NE, rabbit anti-NE; $S$-anti-CHG, sheep anti-cathepsin $\mathrm{G} ; C-A N C A$, serum from a patient with histologically confirmed WG producing cytoplasmic staining in the ANCA IFT; $P$ - $A N C A$ 1-3, three different patients' sera producing (peri-)nuclear staining in the ANCA IFT. $d$, Antigen-catching ELISAs using different MAbs for antigen catching, and saline extract from purified azurophilic granules as the source of antigen.

Release of the C-ANCA antigen upon stimulation of primed neutrophils. As an intracellular protein the C-ANCA antigen in resting neutrophils is not accessible to autoantibodies. However, upon inflammatory stimulation of neutrophils granule constituents can be released or appear on the cell surface. Therefore, we investigated whether stimulation of neutrophils in vitro would lead to membrane expression or exocytosis of the C-ANCA antigen into the incubation medium.

Stimulation of neutrophils with the chemotactic peptide FMLP did not result in release of contents of azurophilic granules (as judged by absence of $\beta$-glucuronidase activity in the supernatant of these cells). In contrast, when cytochalasin B-treated neutrophils were stimulated for 20 min with FMLP, $20 \%$ of $\beta$-glucuronidase activity was recovered in the incuba- tion medium. Western blots of the cell supernatants showed that the C-ANCA antigen had been released from cytochalasin B-treated, FMLP-stimulated neutrophils, but not from untreated, FMLP-stimulated neutrophils (Fig. 11). Membrane expression could not be detected on either resting or stimulated neutrophils (not shown).

\section{Discussion}

In Western blots of solubilized normal donor neutrophils the antigen recognized by C-ANCA was identified as a protein of $M_{\mathrm{r}} 29,000$. Upon subcellular fractionation by Percoll density centrifugation of nitrogen-cavitated neutrophils this C-ANCA antigen was found to copurify with the azurophilic granules, 


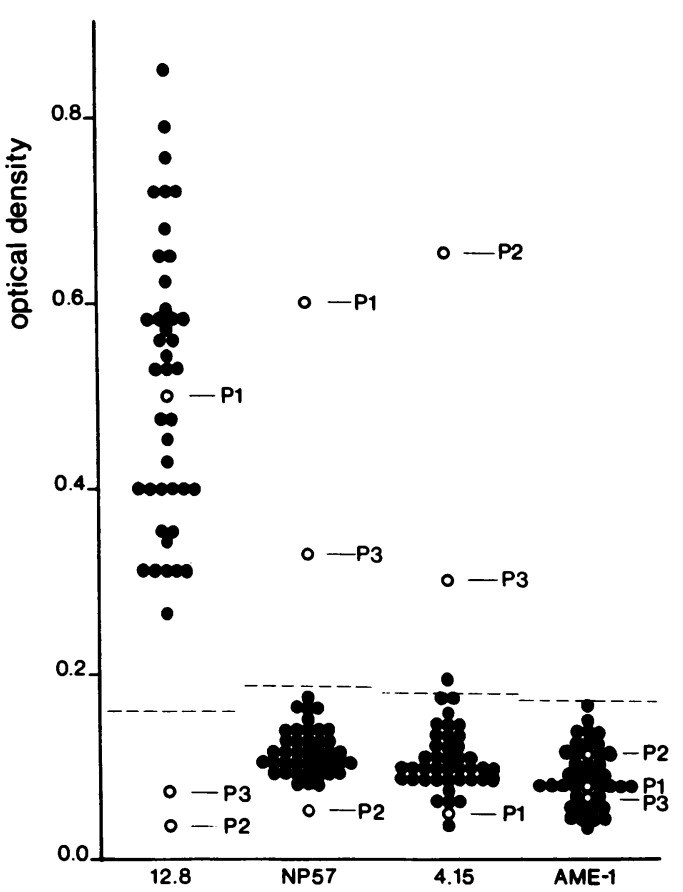

Figure 10. Sandwich ELISA for detection of human antibodies against the C-ANCA antigen triplet caught by MAb 12.8 (IgG1-antiANCA antigen). The control is MAb AME-1 (IgG1-anti-glycophorin A). ๑, C-ANCA-positive WG serum; O, P-ANCA sera 1-3; .--, mean +2 SD of 47 consecutive ANCA-negative patients' sera.

but not with the cytosol fraction or with fractions containing plasma membranes and alkaline phosphatase activity (cf. references 34-37). In the fractions containing the specific granules only trace amounts of C-ANCA antigen were found, caused by contamination of these fractions with small numbers of azurophilic granules, as was indicated by the distribution of $\beta$-glucuronidase activity. Therefore, it is unlikely that ANCA antigen is associated with alkaline phosphatase (34), or that it is located in the specific granules (35). Localization of the C-ANCA antigen in the azurophilic granules is in agreement with its earliest appearance in the promyelocytic differentiation stage of immature myeloid cells (38).

Extraction of purified azurophilic granules with physiological saline solutions showed that the C-ANCA antigen is saline soluble and contained in these granules rather than being associated with the granule membranes. In vitro stimulation of viable, cytochalasin B-treated neutrophils with the chemotactic peptide FMLP indeed caused release of C-ANCA antigen from the cells into the incubation medium, together with the azurophilic granule-enzyme $\beta$-glucuronidase.

Immunochemical analysis of the extracts revealed that the C-ANCA antigen is in fact a protein triplet consisting of a major band of $M_{\mathrm{r}} 29,000$, and two minor bands of 30,500 and 32,000 , each of which appears to carry the antigenic epitope(s) recognized by C-ANCA. The $M_{\mathrm{r}}$ of these bands was not detectably changed after reduction of disulfide bridges. However, in Western blots antigenicity for each of 10 C-ANCA sera tested (and also for MAb 12.8) was invariably destroyed by such treatment (Theunissen, H. J. M., personal communication).

Specific affinity labeling with $\left[{ }^{3} \mathrm{H}\right] \mathrm{DFP}$ indicated that the
FMLP

FMLP-CCB

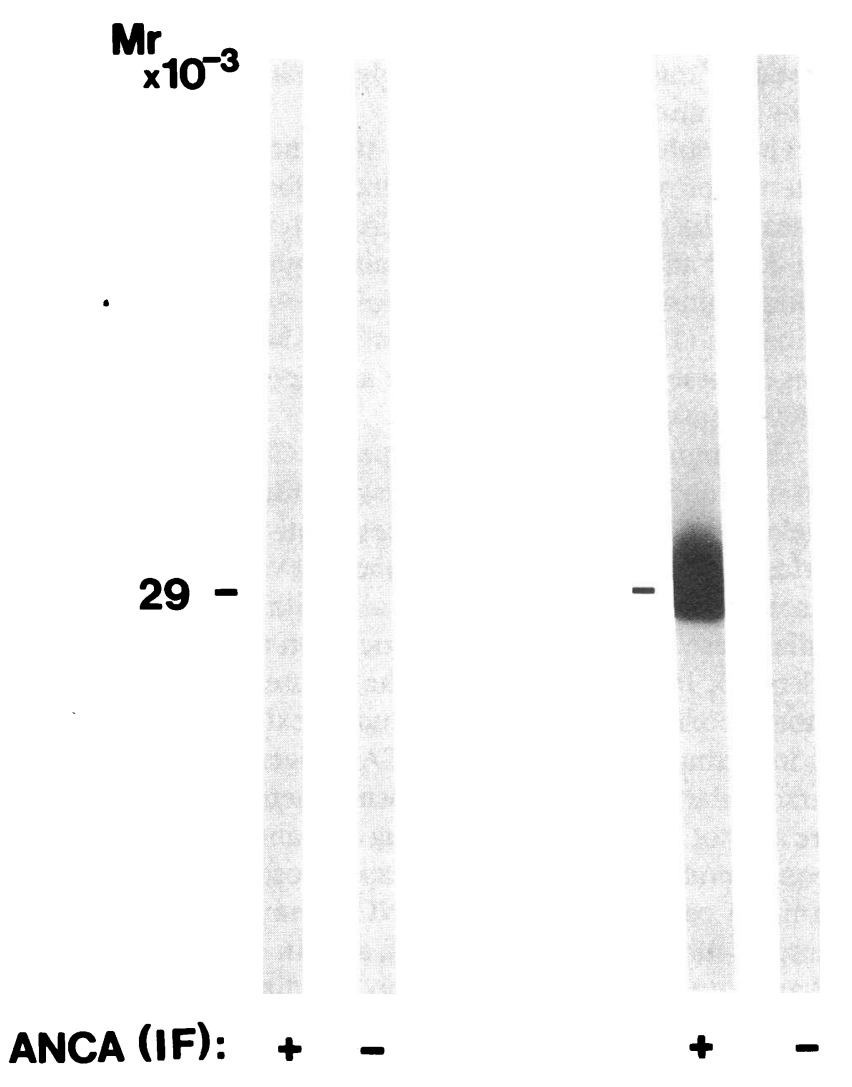

Figure 11. Release of ANCA antigen upon neutrophil stimulation. Concentrated supernatants from neutrophils were analyzed in Western blots for ANCA antigen content. Lane $1+2$, supernatant from neutrophils stimulated with FMLP incubated with C-ANCA-positive (lane 1) and -negative (lane 2) sera; lane $3+4$, supernatant from cytochalasin-B-treated neutrophils, stimulated with FMLP, and analyzed with C-ANCA-positive (lane 3 ) and -negative (lane 4 ) sera. Recovery of $\beta$-glucuronidase was $20 \%$ in the supernatant of cytochalasin-B-treated, FMLP-stimulated cells, and $<3 \%$ in the supernatant of cells, only stimulated with FMLP. In both supernatants lactate dehydrogenase recovery was $<3 \%$.

C-ANCA antigen is a serine protease. However, the C-ANCA antigen could be readily discriminated from elastase and cathepsin $\mathrm{G}$ by their different electrophoretic mobility in SDSPAGE under reducing and nonreducing conditions. $N$-Glycanase treatment showed that C-ANCA antigen is not a glycosylation variant of elastase or cathepsin G. Moreover, C-ANCA-positive patients' sera did not bind to purified NE or cathepsin $\mathrm{G}$ in a solid-phase ELISA.

In addition to elastase and cathepsin G, a third (neutral) protease of neutrophil azurophilic granules has been described as "slowly moving esterolytic activity" or "proteinase 3," and was recently demonstrated to cause emphysema after intratracheal instillation in hamsters (39-41). Proteinase 3 was not available to us during our studies, but in preliminary experiments after the purification protocol described by Kao et al. (41) we obtained evidence that C-ANCA antigen may indeed be identical to proteinase 3. Moreover, Lüdemann et al. (42) have purified C-ANCA antigen from the supernatant of tetra- 
decanoyl phorbol acetate $(1 \mu \mathrm{g} / \mathrm{ml})$ stimulated PMN by immunoaffinity chromatography using purified IgG from a C-ANCA-positive patient's serum and shown that the characteristics of this antigen are strikingly similar to those reported in the literature for proteinase 3.

The results of our study show that the C-ANCA-staining pattern represents a uniform specificity for this 29,000 serine protease. In contrast, the P-ANCA pattern as produced by anti-MPO antibodies $(15,16)$ was also obtained with autoantibodies against elastase (16) or granulocyte-specific antinuclear antibodies (17). Moreover, in some P-ANCA sera combinations of these antibodies, also with anti-29;000 antibodies (CANCA), have been detected.

The originally described WG-specific C-ANCA thus represent only one specificity from a class of autoantibodies against myeloid-specific lysosomal enzymes. Anti-MPO has been reported in association with idiopathic and vasculitis-associated crescentic glomerulonephritis, but also with extrarenal disease. Antielastase was also found in association with vasculitic disorders $(15,16,18,19)$. However, the disease specificity of these autoantibodies has not yet been studied extensively.

In resting neutrophils the ANCA antigens are present only intracellularly and not on the plasma membrane, and therefore are not accessible to circulating autoantibodies. However, upon stimulation neutrophils release lysosomal enzymes and immune complexation with ANCA may occur. Immune complex formation might, in itself, sustain or even amplify an inflammatory process. Alternatively, binding of ANCA might modulate the putative enzymatic function of released ANCA antigen and/or interfere with their inactivation.

In conclusion, cytoplasmic staining neutrophil autoantibodies present in the blood of patients with WG are directed against a soluble and releasable serine protease of azurophilic granules. This serine protease is distinct from elastase and cathepsin $\mathrm{G}$ and may be identical to proteinase 3 . In the blood of patients with vasculitic disorders autoantibodies against other myeloid lysosomal enzymes may also be present, such as anti-MPO or antielastase. Further investigations are necessary to study the putative pathogenetic role of such autoantibodies in these diseases.

\section{Acknowledgments}

F. J. van der Woude (University Hospital, Leiden, The Netherlands) is acknowledged for his role in the initiation of this work. We thank D. Roos for critically reviewing the manuscript, N. Faber for his expert technical assistance, J. G. Huisman, C. de Vries, and M. de Boer for their valuable discussion, J. H. Kramps (University Hospital, Leiden) for providing us with human NE purified from purulent sputum and with rabbit antiserum against elastase, and J. M. Schalkwijk (University Hospital, Nijmegen, The Netherlands) for his gifts of NE and cathepsin G purified from CML cells used in the initial phase of this study. Mrs. J. Gerritsen is gratefully acknowledged for preparing the typescript and Mrs. P. J. van Proosdij is thanked for her artwork. We thank K. M. Dolman for his excellent support during completion of this work.

\section{References}

1. Cupps, T. R., and A. S. Fauci. 1981. Wegener's granulomatosis. In Major Problems in Internal Medicine, Vol. XXI. L. H. Smith, Jr., editor. W. B. Saunders Company, Philadelphia. 72-87.
2. Fauci, A. S., B. F. Haynes, P. Katz, and S. M. Wolff. 1983. Wegener's granulomatosis, prospective clinical and therapeutic experience with 85 patients for 21 years. Ann. Intern. Med. 98:76-85.

3. Fauci, A. S., and S. M. Wolff. 1973. Wegener's granulomatosis: studies in 18 patients and a review of the literature. Medicine (Baltimore). 52:535-561.

4. van der Woude, F. J., L. Arisz, S. Meijer, A. J. M. Donker, Ph. J. Hoedemaeker, and J. J. M. van Overbeek. 1978. Wegener's granulomatosis: a clinicopathological study in twelve patients. Neth. J. Med. 21:205-220.

5. Pinching, A. J., A. J. Rees, B. A. Pussell, C. M. Lockwood, R. S. Mitchinson, and D. K. Peters. 1980. Relapses in Wegener's granulomatosis: the role of infection. Br. Med. J. 281:836-838.

6. DeRemee, R. A., T. J. McDonald, and L. H. Weiland. 1985. Wegener's granulomatosis: observations on treatment with antimicrobial agents. Mayo Clin. Proc. 60:27-32.

7. West, B. C., J. R. Todd, and J. W. King. 1987. Wegener's granulomatosis and trimethoprim-sulfamethoxazole: complete remission after a twenty-year course. Ann. Intern. Med. 106:840-842.

8. Davies, D. J., J. E. Moran, J. F. Niall, and G. B. Ryan. 1982. Segmental necrotising glomerulonephritis with antineutrophil antibody: possible arbovirus aetiology? Br. Med. J. 285:606

9. Rasmussen, N., and A. Wiik. 1985. Autoimmunity in Wegener's granulomatosis. In Immunobiology, Autoimmunity, Transplantation in Otorhinolaryngology. J. E. Veldman, B. F. McCabe, E. H. Huizing, and N. Mygind, editors. Kugler, Amsterdam. 207-212.

10. van der Woude, F. J., N. Rasmussen, S. Lobatto, A. Wiik, H. Permin, L. A. van Es, M. van der Giessen, G. K. van der Hem, and T. H. The. 1985. Autoantibodies against neutrophils and monocytes: tool for diagnosis and marker of disease activity in Wegener's granulomatosis. Lancet. i:425-429.

11. Gross, W. L., G. Lüdemann, G. Kiefer, and H. Lehmann. 1986. Anticytoplasmic antibodies in Wegener's granulomatosis. Lancet. i:806.

12. Lüdemann, G., and W. L. Gross. 1987. Autoantibodies against cytoplasmic structures of neutrophil granulocytes in Wegener's granulomatosis. Clin. Exp. Immunol. 69:350-357.

13. Savage, C. O. S., S. Jones, C. G. Winearls, P. D. Marshall, and C. M. Lockwood. 1987. Prospective study of radioimmunoassay for antibodies against neutrophil cytoplasm in diagnosis of systemic vasculitis. Lancet. i:1389-1393.

14. Cohen Tervaert, J. W., C. G. M. Kallenberg, M. van der Giessen, F. J. van der Woude, and G. K. van der Hem. 1987. Anticytoplasmic antibodies: a marker for disease activity in Wegener's granulomatosis. Kidney Int. 32:778-779. (Abstr.)

15. Falk, R. J., and J. C. Jennette. 1988. Anti-neutrophil cytoplasmic autoantibodies with specificity for myeloperoxidase in patients with systemic vasculitis and idiopathic necrotizing and crescentic glomerulonephritis. N. Engl. J. Med. 318:1651-1657.

16. Goldschmeding, R., J. W. Cohen Tervaert, C. E. van der Schoot, M. van der Giessen, A. E. G. Kr. von dem Borne, and C. G. M. Kallenberg. 1988. Autoantibodies against myeloid lysosomal enzymes: a novel class of autoantibodies associated with vasculitic syndromes. Kidney Int. (Abstr.) 34:558-559.

17. Wiik, A. 1980. Granulocyte-specific antinuclear antibodies Allergy (Copenh.). 35:263-289.

18. Cohen Tervaert, J. W., R. Goldschmeding, J. D. Elema, M. Van der Giessen, M. G. Huitema, G. K. Van der Hem, T. H. The A. E. G. Kr. von dem Borne, and C. G. M. Kallenberg. 1989. Both vasculitis-associated and idiopathic crescentic glomerulonephritis are associated with autoantibodies against myeloid lysosomal enzymes. Kidney Int. In press.

19. Gans, R. O. B., R. Goldschmeding, A. J. M. Donker, S. J. Hoorntje, M. C. Huizinga, J. W. Cohen Tervaert, C. G. M. Kallenberg, and A. E. G. Kr. von dem Borne, 1989. Neutrophil cytoplasmic autoantibodies and Wegener's granulomatosis. Lancet. i:269-270.

20. Wormsley, S. B., R. J. Leavitt, J. B. Peter, F. N. Boctor, and A. S. Fauci. 1988. Antineutrophil cytoplasm antibodies (ANCA) in 
systemic vasculitis: clinical utility of quantitation by flow cytometry. Arthritis Rheum. 31:S34. (Abstr.)

21. McCluskey, R. T., and R. Fienberg. 1983. Vasculitis in primary vasculitides, granulomatoses and connective tissue diseases. Hum. Pathol. 14:305-315.

22. Martodam, R. R., R. J. Baugh, D. Y. Twumasi, and I. E. Liener. 1979. A rapid procedure for the large-scale purification of elastase and cathepsin $\mathrm{G}$ from human sputum. Prep. Biochem. 9:15-31.

23. Feinstein, G., and A. Janoff. 1975. A rapid method of purification of human granulocyte cationic neutral proteases: purification and characterization of human granulocyte chymotrypsin-like enzyme. Biochim. Biophys. Acta. 403:477-492.

24. Feinstein, G., and A. Janoff. 1975. A rapid method of purification of human granulocyte cationic neutral proteases: purification and further characterization of human granulocyte elastase. Biochim. Biophys. Acta. 403:493-505.

25. Goldschmeding, R., C. E. van der Schoot, M. A. van der Snoek, and A. E. G. Kr. von dem Borne. 1988. A monoclonal antibody against the 29-kD ANCA-antigen: application as catching antibody in a sandwich ELISA for ANCA detection. Proc. First Int. Workshop on ANCA: APMIS. 97 (Suppl 6):47.

26. Pulford, K. A. F., W. N. Erber, J. A. Crick, I. Olsson, K. J. Micklem, K. C. Gatter, and D. Y. Mason. 1988. Use of monoclonal antibody against human neutrophil elastase in normal and leukemia myeloid cells. J. Clin. Pathol. 41:853-860.

27. Verheugt, F. W. A., A. E. G. Kr. von dem Borne, F. Décary, and C. P. E. Engelfriet. 1977. The detection of granulocyte alloantibodies with an indirect immunofluorescence test. $\mathrm{Br}$. J. Haematol. 36:533-544.

28. Voetman, A. A., R. S. Weening, M. N. Hamers, L. J. Meerhof, A. A. A. M. Bot, and D. Roos. 1981. Phagocytosing human neutrophils inactivate their own granular enzymes. J. Clin. Invest. 67:15411549.

29. Borregaard, N., J. M. Heiple, F. R. Simons, and R. A. Clark. 1983. Subcellular localisation of the b-cytochrome component of the human neutrophil microbicidal oxidase translocation during activation. J. Cell Biol. 97:52-61.

30. van der Schoot, C. E., M. Wester, A. E. G. Kr. von dem Borne, and J. G. Huisman. 1986. Characterization of platelet-specific alloantigens by immunoblotting: localization of $\mathrm{Zw}$ and Bak antigens. $\mathrm{Br}$. $J$. Haematol. 64:715-723.
31. Fraker, P. J., and J. C. Speck. 1978. Protein and cell membrane iodination with sparingly soluble chloramide-1,3,4,5-tetrachlor$3 \alpha, 6 \alpha$-diphenyl glycouril. Biochem. Biophys. Res. Commun. 80:849857.

32. Huisman, J. G., I. N. Winkel, P. N. Lelie, M. Tersmette, J. Goudsmit, and F. Miedema. 1987. Detection of early anti-p24 HIV responses in EIA- and immunoblot-negative individuals. Vox Sang. 53:31-36.

33. Elder, J. H., and S. Alexander. 1982 . Endo- $\beta-N$-Acetylglucosaminidase F: endoglycosidase from flavobacterium meningosepticum that cleaves both high mannose and complex glycoproteins. Proc. Natl. Acad. Sci. USA. 79:4540-4544.

34. Lockwood, C. M., S. Jones, D. W. Moss, E. Bakes, K. B. Whitaker, and C. O. S. Savage. 1987. Association of alkaline phosphatase with an autoantigen recognized by circulating anti-neutrophil antibodies in systemic vasculitis. Lancet. i:716-720.

35. Gross, W. L., J. Lüdemann, and J. M. Lüdemann. 1987. Antineutrophil-cytoplasm antibodies in Wegener's granulomatosis are not directed against alkaline phosphatase. Lancet. i:1488-1489.

36. Rasmussen, N., N. Borregaard, and A. Wiik. 1987. Antineutrophil-cytoplasm antibodies in Wegener's granulomatosis are not directed against alkaline phosphatase. Lancet. i:1488.

37. Goldschmeding, R., P. A. T. Tetteroo, A. E. G. Kr. von dem Borne, and C. G. M. Kallenberg. 1987. Antineutrophil-cytoplasm antibodies in Wegener's granulomatosis are not directed against alkaline phosphatase. Lancet. i: 1489.

38. Goldschmeding, R., P. A. T. Tetteroo, A. E. G. Kr. von dem Borne, and T. H. The. 1987. Wegener's granulomatosis autoantibodies: serological and immunochemical characterization of the antigen. Br. J. Haematol. 66:411. (Abstr.)

39. Sweetman, F., and L. Ornstein. 1974. Electrophoresis of elastase-like esterases from human neutrophils. J. Histochem. Cytochem. 22:327-339.

40. Dewald, B., R. Rindler-Ludwig, U. Bretz, and M. Baggiolini. 1975. Subcellular localization and heterogeneity of neutral proteases in neutrophilic polymorphonuclear leukocytes. J. Exp. Med. 131:709722.

41. Kao, R. C., M. G. Wehner, K. M. Skubitz, B. H. Gray, and J. R. Hordal. 1988. Proteinase 3. A distinct human polymorphonuclear leucocyte proteinase that produces emphysema in hamsters. J. Clin. Invest. 82:1963-1973.

42. Lüdemann, J., B. Utecht, and W. L. Gross. 1989. The target antigen of ACPA is Proteinase 3. Neth. J. Med. (Suppl). In press. 